\title{
A clinical tool to measure trunk control in children with cerebral palsy: The Trunk Control Measurement Scale
}

\author{
Lieve Heyrman a,*, Guy Molenaers ${ }^{\mathrm{b}, \mathrm{c}}$, Kaat Desloovere ${ }^{\mathrm{a}, \mathrm{c}}$, Geert Verheyden ${ }^{\mathrm{d}}$, \\ Jos De Cat ${ }^{\mathrm{e}}$, Elegast Monbaliu ${ }^{\mathrm{a}}$, Hilde Feys ${ }^{\mathrm{a}}$

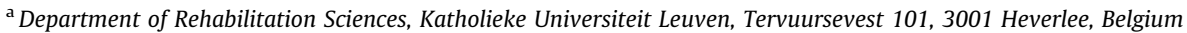 \\ ${ }^{\mathrm{b}}$ Department of Orthopaedics, University Hospital of Pellenberg, Weligerveld 1, 3212 Pellenberg, Belgium \\ ${ }^{c}$ Clinical Motion Analysis Laboratory, University Hospital of Pellenberg, Weligerveld 1, 3212 Pellenberg, Belgium \\ ${ }^{\mathrm{d}}$ Hochschule für Gesundheit, University of Applied Sciences, Universitätstraße 105, 44789 Bochum, Germany \\ ${ }^{\mathrm{e}}$ Department of Rehabilitation, University Hospital of Pellenberg, Weligerveld 1, 3212 Pellenberg, Belgium
}

\section{A R T I C L E I N F O}

Article history:

Received 19 June 2011

Accepted 19 June 2011

Available online 14 July 2011

\section{Keywords:}

Cerebral palsy

Trunk control

Measurement scale

Reliability

Validity

\begin{abstract}
A B S T R A C T
In this study the psychometric properties of the Trunk Control Measurement Scale (TCMS) in children with cerebral palsy (CP) were examined. Twenty-six children with spastic CP (mean age 11 years 3 months, range 8-15 years; Gross Motor Function Classification System level I $n=11$, level II $n=5$, level III $n=10$ ) were included in this study. To determine the discriminant ability of the TCMS, 30 typically developing (TD) children (mean age 10 years 6 months, range 8-15 years) were also included. For inter-rater reliability, two testers scored all children simultaneously. To determine test-retest reliability, participants were reassessed on a second test occasion. For construct validity, the Gross Motor Function Measure (GMFM) was administered. Intraclass correlation coefficients (ICC) ranged from 0.91 to 0.99 for inter-rater and test-retest reliability. Kappa and weighted kappa values ranged for all but one item from 0.45 to 1 . The standard error of measurement was $2.9 \%$ and $3.4 \%$, and the smallest detectable difference for repeated measurements was $8 \%$ and $9.43 \%$ between raters and test-retest, respectively. Cronbach's alpha coefficients ranged from 0.82 to 0.94 . Spearman rank correlation with the GMFM was 0.88 and increasing coefficients were found from dimension B to E. Subscale and total TCMS scores showed significant differences between children with CP and TD children $(p<0.0001)$. The results support the reliability and validity of the TCMS in children with spastic CP. The scale gives insight into the strengths and weaknesses of the child's trunk performance and therefore can have valuable clinical use.
\end{abstract}

(c) 2011 Elsevier Ltd. All rights reserved.

\section{Introduction}

Children with cerebral palsy (CP) frequently show impaired trunk control, which can affect performances of activities of daily life such as sitting, reaching and walking (Hadders-Algra \& Brogren, 2008; Prosser, Lee, VanSant, Barbe, \& Lauer, 2010; van der Heide et al., 2005). Nevertheless, the majority of research in children with CP is focused on assessment and treatment of upper and lower extremities (Damiano, Alter, \& Chambers, 2009; Klingels et al., 2010). In contrast, literature on trunk control in children with $\mathrm{CP}$ is scarce.

To understand impairments in trunk control, and to guide and evaluate treatment interventions, standardized measurement tools are indispensable. Only a limited number of clinical tools exist to measure trunk control in children

\footnotetext{
* Corresponding author. Tel.: +32 163290 35; fax: +32 16329197.

E-mail address: Lieve.Heyrman@faber.kuleuven.be (L. Heyrman).
} 
with CP. Some measurement scales evaluate static postural alignment in sitting only, such as the Seated Postural Control Measure (SPCM) (Fife et al., 1991) and the Spinal Alignment and Range of Motion Measure (SAROMM) (Bartlett \& Purdie, 2005). The SPCM has poor reliability and the SAROMM provides information on postural characteristics of the trunk only, and not on trunk control in a static or dynamic condition. Recently, a refined version of the Segmental Assessment of Trunk Control (SATCo) (Butler, Saavedra, Sofranac, Jarvis, \& Woollacott, 2010) was published. This assessment tool scores the ability to maintain a stable sitting position on a dichotomous scale throughout three conditions (during supported sitting, during head movements and during external perturbations), and with gradually decreasing support of the trunk. Once a child has achieved independent sitting in these three conditions, the maximum score on the scale is already obtained. Also, the SATCo covers static trunk control only; items evaluating dynamic trunk control are not included. In summary, it appears that these above-mentioned scales are not comprehensive enough to evaluate both the static and dynamic aspect of trunk control needed to perform functional activities. Furthermore, these scales contain quantitative items to measure their outcome, not taking into account the performance itself but only the result. Therefore, clinical interpretation of these measurements is more difficult. Interestingly, in the area of adult neurological rehabilitation, several measures of trunk control are available (Verheyden, Nieuwboer, Van de Winckel, \& De Weerdt, 2007). In particular, the Trunk Impairment Scale (TIS) (Verheyden et al., 2004) measures both static and dynamic aspects of trunk control in sitting and has demonstrated good psychometric properties for use in clinical practice and research. The scale was developed to score trunk performance in sitting in people with stroke. Just recently, the reliability of the TIS was examined in children with CP (Sæther and Jørgensen, 2011) with good intra- and interobserver reliability results. However, the validity of the scale was not verified.

In this current study, we also explored whether the TIS could serve as a basis for evaluation of trunk control in children with CP. Although the content of the items of the TIS was found to be relevant to measure trunk control in children with CP, some important limitations due to the specific clinical features of impaired trunk control in CP were noticed. Therefore, we developed a new measurement scale, the Trunk Control Measurement Scale (TCMS), based on the TIS but in accordance with the clinical features of impaired trunk control in children with CP.

The first aim of this study was to develop a clinical measurement scale comprehensive enough to evaluate both the static and dynamic aspect of trunk control in children with CP. The second aim was to examine its intra- and interobserver reliability, internal consistency and the content and construct validity. Also, the ability of the TCMS to discriminate between children with CP and TD children was evaluated.

\section{Methods}

\subsection{Development of the Trunk Control Measurement Scale}

The Trunk Impairment Scale (TIS) was used as a starting point for development of the TCMS. Firstly, we addressed the content validity: the original version of the TIS was applied to 14 children with $\mathrm{CP}$, and existing clinical scales (Bartlett \& Birmingham, 2003; Franjoine, Gunther, \& Taylor, 2003; Russell, Rosenbaum, Gowland, \& Hardy, 1993) and books on neurorehabilitation (Carr \& Sheperd, 1998; Stamer, 2000) were consulted. Based on this information, a revised scale was prepared and its content was thoroughly discussed with a team of clinical experts (medical doctors, physiotherapists, movement scientists) of the Cerebral Palsy care centre (University Hospital of Pellenberg, Leuven). The TCMS was then constructed, based on the TIS, but with adaptations and additions to accord with the clinical features of impaired trunk control in children with CP. First, stroke leads to unilateral involvement of the body whereas in children with CP both unilateral and bilateral involvement occurs. The ability to measure both left and right side could reveal some asymmetry in performance, which is not covered in all subscales of the TIS. Also, the items of the subscales 'dynamic sitting balance' and 'co-ordination' of the TIS evaluate selective movements of the trunk in the frontal and transversal plane, but children with CP also often have difficulties with trunk movements in the sagittal plane. Finally, all items of the TIS are performed within the base of support so an important dynamic aspect of trunk control, i.e. being an active segment that contributes to movements beyond the base of support, is not covered by the items of the TIS.

In a second step, this revised scale was administered to 15 typically developing (TD) children and 7 children with CP to further adjust item selection and description of scoring criteria. Finally, a pilot inter-rater reliability study was performed in 16 children with CP. Based on these results, test instructions and scoring criteria were further adapted and the TCMS was finalized for the current study.

The TCMS (Appendix A) measures two main components of trunk control during functional activities: (a) being a stable base of support, and (b) being an actively moving body segment. Therefore, the scale consists of two sections: static sitting balance and dynamic sitting balance. The second section is further divided into two subscales: selective movement control and dynamic reaching. The 'static sitting balance' subscale evaluates static trunk control during movements of upper and lower limbs. The subscale 'selective movement control' measures selective trunk movements in three planes (flexion/ extension, lateral flexion, rotation) within the base of support. The subscale 'dynamic reaching' evaluates the performance during three reaching tasks, requiring active trunk movements beyond the base of support. The total scale contains 15 items, with the subscales consisting of five, seven and three items, respectively. All items are scored on a two-, three- or four-point ordinal scale and administered bilaterally in case of clinical relevance. The total score of the TCMS ranges from 0 to 58 , with a higher score indicating a better performance. 


\subsection{Reliability study}

\subsubsection{Participants}

The study population consisted of 26 children with CP. Fifteen participants were recruited from two special education schools and 11 participants from three large private practices. Participants were included in the study if they were diagnosed with spastic CP, aged between 8 and 15 years, able to sit without trunk and feet support for at least 30 min, and able to understand the test instructions. Exclusion criteria were other diagnosis of $\mathrm{CP}$, orthopaedic interventions and botulinum toxin injections performed in the last 6 months, and implantation of an intrathecal baclofen pump. Children who participated in the pilot inter-rater reliability study were not included in this study.

To examine the discriminant ability of the TCMS, 30 typically developing (TD) children between 8 and 15 years were also included in this study. The children were recruited from several mainstream education schools. The presence of any musculoskeletal or neurological disorder was an exclusion criterion for participation.

Ethical approval was granted by the Ethics Committee of the University Hospital of Leuven. Informed consent was obtained from parents and children.

\subsubsection{Testing procedure}

To examine inter-rater reliability, two trained physiotherapists assessed all children with $\mathrm{CP}$ on a first test occasion. Each rater gave test instructions to half of the participants. Allocation of the participants to the raters was randomized. The TCMS was scored simultaneously but independently. To determine test-retest reliability, the children with $\mathrm{CP}$ were reassessed on a second test occasion by the rater who gave the test instructions on the first test occasion. The test-retest interval was on average 10 days (range $3-21$ days) to minimize recall bias.

The Gross Motor Function Measure (GMFM) (Russell, Rosenbaum, Gowland, \& Hardy, 1993) was also administered in the children with CP on the second test occasion. The GMFM is a reliable and validated tool for assessment of gross motor function in children with CP. It consists of 88 items, divided into five dimensions: lying and rolling (A), sitting (B), crawling and kneeling (C), standing (D), and walking, running and jumping (E). Dimension scores and total score are calculated as percentages.

The typically developing children were evaluated with the TCMS on a single test occasion.

\subsubsection{Statistical analysis}

Inter-rater and test-retest reliability for the subscales and the total TCMS was determined by intraclass correlation coefficients (ICC). The reliability for each item separately was assessed by Cohen's kappa (dichotomous items) or weighted kappa (polytomous items) values, and percentages of agreement. The 95\% confidence intervals (CI) for ICC, kappa and weighted kappa coefficients were calculated. ICC values $>0.90$ were considered excellent, $0.75-0.90$ good and $<0.75$ as poor to moderate (Portney \& Watkins, 2009). Kappa values $>0.80$ were considered excellent, 0.61-0.80 substantial, 0.41-0.60 moderate and $<0.41$ poor (Landis \& Koch, 1977). Inter-rater and test-retest agreement was further examined using the method of Bland and Altman (Bland \& Altman, 1986).

To investigate the internal consistency of the total TCMS and subscales, Cronbach's alpha was calculated. Cronbach's alpha should approach 0.90 to consider satisfactory internal consistency (Portney \& Watkins, 2009).

The Standard Error of Measurement (SEM) and Smallest Detectable Difference (SDD) were calculated by using following formulae: $\mathrm{SEM}=S D \times \sqrt{(1-\mathrm{ICC})}$ and $\mathrm{SDD}=\mathrm{SEM} \times 1.96 \sqrt{2}$ (Portney \& Watkins, 2009).

To evaluate construct validity, TCMS subtotals and total score were compared with dimensions scores and total score of the GMFM by means of Spearman rank correlation coefficients. Values of the correlation coefficients were considered very high between 0.91 and 1.0 , high between 0.71 and 0.90 , moderate between 0.51 and 0.70 , low between 0.31 and 0.50 and little below 0.30 (Hinkle, Wiersma, \& Jurs, 1998).

Finally, the discriminant ability was assessed by comparing the subscale scores and total scores of the children with $\mathrm{CP}$ with the TD children by use of a Wilcoxon ranked sum test. For this comparison, data from the first test occasion of the children with CP were used.

The level of significance for all analyses was set at $p<0.05$. Statistical analyses were conducted with the statistical software program SAS Enterprise Guide 4.2.

\section{Results}

\subsection{Participants}

Twenty-six children with CP (13 males, 13 females) with a mean age of 11 years 3 months (SD 2y, range 8y 3mo-15y 3mo) were included in the study. Seventeen children had a diplegia, seven children a hemiplegia and two children a quadriplegia. According to the Gross Motor Function Classification System (GMFCS) (Palisano et al., 1997), 11 children were classified as level I, 5 as level II and 10 as level III. Sixteen children attended special education schools and 10 children attended mainstream schools. Two children could not be reassessed on the second test occasion because of illness. Therefore, the analysis for test-retest reliability was based on 24 children.

The TD children $(N=30)$ consisted of 17 males and 13 females. The mean age was 10 years 6 months (SD 2y, range $8 \mathrm{y}$ $1 \mathrm{mo}-15 \mathrm{y} 7 \mathrm{mo})$. 


\subsection{Inter-rater and test-retest reliability}

ICC and 95\% CI for the total score of TCMS and its subscales are presented in Table 1. The total score of the TCMS showed excellent reliability with an ICC of 0.98 for inter-rater reliability and 0.97 for test-retest reliability. Subscales ICCs ranged from 0.94 to 0.99 for inter-rater reliability and from 0.91 to 0.94 for test-retest reliability.

Kappa and weighted kappa values and percentages of agreement are presented in Table 2. For the static sitting balance subscale, substantial to excellent reliability coefficients were found for all items, except for inter-rater reliability of item 5 on the right side $(\kappa \omega=0.59)$. For the selective movement control subscale, reliability ranged from moderate to excellent, except for subitem $9 c$ for inter-rater reliability, and for subitems $9 b$ and $9 c$ for test-retest reliability. For subitems 7a, $8 c$ and $9 a$ on

Table 1

Intraclass correlation coefficients and 95\% confidence intervals between raters and test-retest for the total Trunk Control Measurement Scale and subscales.

\begin{tabular}{|c|c|c|c|c|}
\hline & \multicolumn{2}{|c|}{ Inter-rater agreement } & \multicolumn{2}{|c|}{ Test-retest agreement } \\
\hline & ICC & $95 \% \mathrm{CI}$ & ICC & $95 \% \mathrm{CI}$ \\
\hline Static sitting balance & 0.98 & $0.96-1.00$ & 0.94 & $0.87-0.97$ \\
\hline Selective movement control & 0.94 & $0.87-0.97$ & 0.91 & $0.81-0.96$ \\
\hline Dynamic reaching & 0.99 & $0.99-1.00$ & 0.92 & $0.82-0.96$ \\
\hline Total TCMS & 0.98 & $0.95-0.99$ & 0.97 & $0.93-0.99$ \\
\hline
\end{tabular}

ICC - intraclass correlation coefficient; CI - confidence interval; TCMS - Trunk Control Measurement Scale.

Table 2

Kappa or weighted kappa values with 95\% confidence intervals and percentages of agreement between raters and test-retest for the items of the Trunk Control Measurement Scale.

\begin{tabular}{|c|c|c|c|c|c|c|c|}
\hline \multirow[t]{2}{*}{ Item } & \multirow[t]{2}{*}{$\kappa / \kappa \omega$} & \multicolumn{3}{|c|}{ Inter-rater agreement } & \multicolumn{3}{|c|}{ Test-retest agreement } \\
\hline & & Value & $95 \% \mathrm{CI}$ & $\%$ & Value & $95 \% \mathrm{CI}$ & $\%$ \\
\hline \multicolumn{8}{|c|}{ Static sitting balance } \\
\hline Item 1 & $\kappa$ & 1.00 & - & $100 \%$ & 1.00 & - & $100 \%$ \\
\hline Item 2 & $\kappa$ & 0.87 & $0.61-1.00$ & $96 \%$ & 0.60 & $0.21-0.99$ & $88 \%$ \\
\hline Item 3 left & $\kappa$ & 1.00 & - & $100 \%$ & 1.00 & - & $100 \%$ \\
\hline Item 3 right & $\kappa$ & 1.00 & - & $100 \%$ & 1.00 & - & $100 \%$ \\
\hline Item 4 left & $\kappa \omega$ & 1.00 & - & $100 \%$ & 0.71 & $0.52-0.91$ & $79 \%$ \\
\hline Item 4 right & $\kappa \omega$ & 0.95 & $0.85-1.00$ & $96 \%$ & 0.87 & $0.71-1.00$ & $92 \%$ \\
\hline Item 5 left & $\kappa \omega$ & 0.60 & $0.35-0.86$ & $65 \%$ & 0.83 & $0.67-0.98$ & $88 \%$ \\
\hline Item 5 right & $\kappa \omega$ & 0.59 & $0.32-0.86$ & $69 \%$ & 0.75 & $0.56-0.93$ & $83 \%$ \\
\hline \multicolumn{8}{|c|}{ Selective movement control } \\
\hline Item 6a & $\kappa$ & 1.00 & - & $100 \%$ & 1.00 & - & $100 \%$ \\
\hline Item $6 b$ & $\kappa$ & 0.76 & $0.51-1.00$ & $88 \%$ & 0.65 & $0.34-0.96$ & $83 \%$ \\
\hline Item 7a & $\kappa$ & 1.00 & - & $100 \%$ & $*$ & * & $92 \%$ \\
\hline Item $7 \mathrm{~b}$ & $\kappa$ & 1.00 & - & $100 \%$ & 0.80 & $0.53-1.00$ & $92 \%$ \\
\hline Item 8a left & $\kappa$ & 1.00 & - & $100 \%$ & 0.86 & $0.60-1.00$ & $96 \%$ \\
\hline Item 8a right & $\kappa$ & 1.00 & - & $100 \%$ & 0.65 & $0.31-1.00$ & $88 \%$ \\
\hline Item 8b left & $\kappa$ & 0.66 & $0.36-0.96$ & $85 \%$ & 0.83 & $0.61-1.00$ & $92 \%$ \\
\hline Item $8 \mathrm{~b}$ right & $\kappa$ & 0.68 & $0.38-0.97$ & $85 \%$ & 0.57 & $0.23-0.90$ & $79 \%$ \\
\hline Item $8 c$ left & $\kappa$ & 0.78 & $0.37-1.00$ & $96 \%$ & 0.45 & -0.18 to 1.00 & $92 \%$ \\
\hline Item $8 c$ right & $\kappa$ & 0.65 & $0.02-1.00$ & $96 \%$ & $*$ & $*$ & $92 \%$ \\
\hline Item 9a left & $\kappa$ & 0.65 & $0.02-1.00$ & $96 \%$ & 1.00 & - & $100 \%$ \\
\hline Item 9a right & $\kappa$ & 0.65 & $0.02-1.00$ & $96 \%$ & $*$ & $*$ & $96 \%$ \\
\hline Item 9b left & $\kappa \omega$ & 0.49 & $0.18-0.80$ & $69 \%$ & 0.44 & $0.09-0.78$ & $75 \%$ \\
\hline Item 9b right & $\kappa \omega$ & 0.56 & $0.24-0.87$ & $73 \%$ & 0.38 & $0.10-0.67$ & $63 \%$ \\
\hline Item 9c left & $\kappa$ & 0.28 & -0.13 to 0.69 & $73 \%$ & 0.24 & -0.21 to 0.69 & $75 \%$ \\
\hline Item 9c right & $\kappa$ & 0.23 & -0.09 to 0.54 & $65 \%$ & 0.05 & -0.35 to 0.46 & $63 \%$ \\
\hline Item 10a & $\kappa \omega$ & 0.51 & $0.22-0.80$ & $69 \%$ & 0.79 & $0.56-1.00$ & $88 \%$ \\
\hline Item 10b & $\kappa$ & 0.80 & $0.55-1.00$ & $92 \%$ & 0.47 & $0.16-0.78$ & $75 \%$ \\
\hline Item 11a & $\kappa \omega$ & 0.58 & $0.32-0.84$ & $77 \%$ & 0.80 & $0.57-1.00$ & $88 \%$ \\
\hline Item 11b & $\kappa$ & 0.79 & $0.51-1.00$ & $92 \%$ & 0.78 & $0.49-1.00$ & $92 \%$ \\
\hline Item 12a & $\kappa \omega$ & 0.86 & $0.75-0.98$ & $85 \%$ & 0.82 & $0.67-0.96$ & $79 \%$ \\
\hline Item 12b & $\kappa$ & 0.75 & $0.43-1.00$ & $92 \%$ & 0.60 & $0.21-0.99$ & $88 \%$ \\
\hline \multicolumn{8}{|c|}{ Dynamic reaching } \\
\hline Item 13 & $\kappa \omega$ & 0.94 & $0.82-1.00$ & $96 \%$ & 0.71 & $0.47-0.96$ & $83 \%$ \\
\hline Item 14 left & $\kappa \omega$ & 0.92 & $0.82-1.00$ & $92 \%$ & 0.71 & $0.48-0.93$ & $75 \%$ \\
\hline Item 14 right & $\kappa \omega$ & 0.96 & $0.89-1.00$ & $96 \%$ & 0.59 & $0.31-0.87$ & $75 \%$ \\
\hline Item 15 left & $\kappa \omega$ & 0.96 & $0.88-1.00$ & $96 \%$ & 0.74 & $0.50-0.98$ & $83 \%$ \\
\hline Item 15 right & $\kappa \omega$ & 0.96 & $0.88-1.00$ & $96 \%$ & 0.87 & $0.68-1.00$ & $92 \%$ \\
\hline
\end{tabular}

$\kappa / \kappa \omega$ - Cohen's kappa $(\kappa) /$ weighted kappa $(\kappa \omega)$; Value - value of kappa or weighted kappa; CI - confidence interval; \% - percentage of agreement; * not able to calculate. 

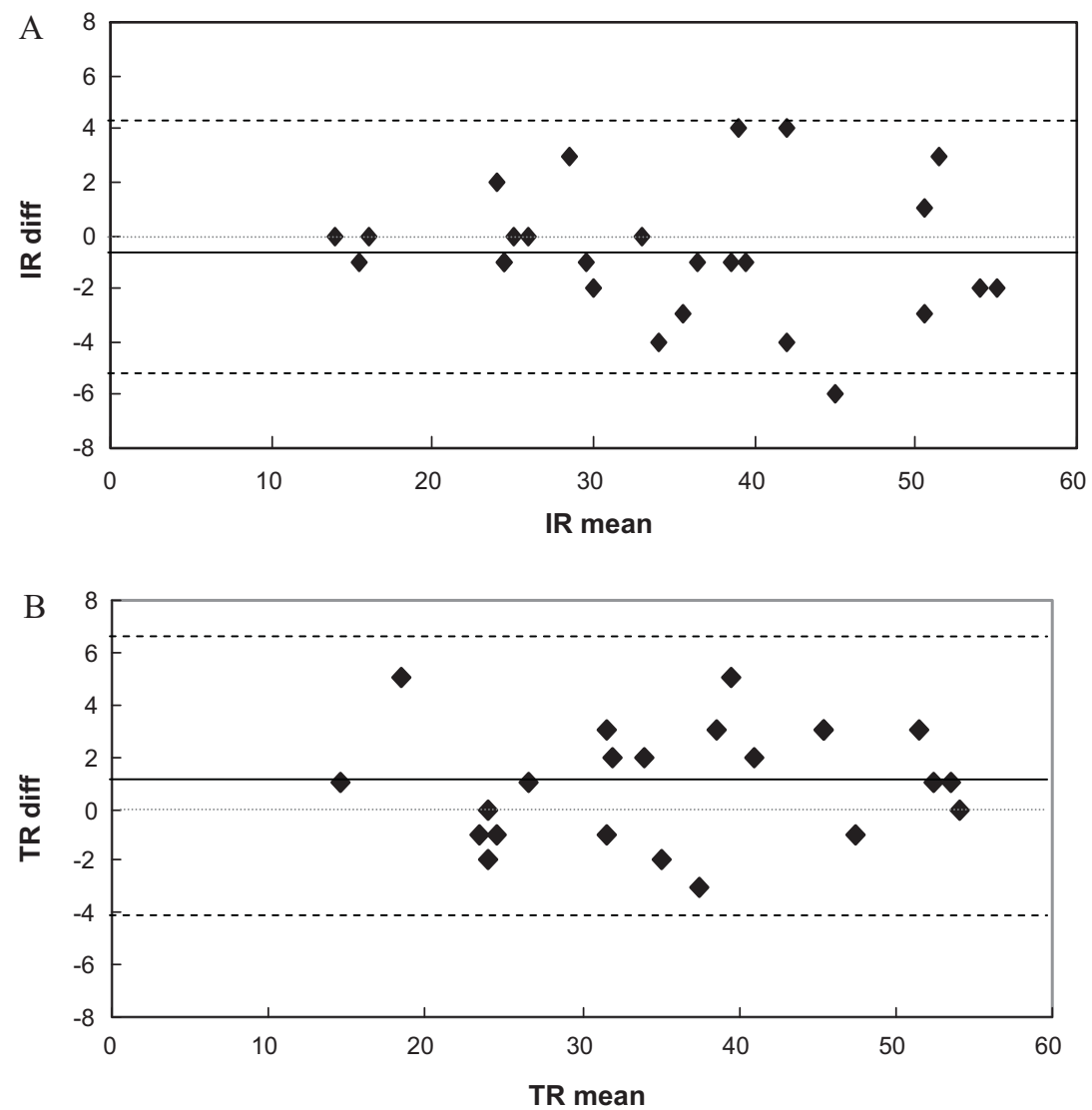

Fig. 1. Bland-Altman plots of range of differences between raters (IRdiff) against range of mean scores of raters (IRmean) (A); and range of differences between test-retest (TRdiff) against range of mean scores between test-retest (TRmean)(B). Solid line represents mean of differences; dashed lines limits of agreement.

the right side, kappa values could not be calculated because of skewed distribution of data. Percentages of agreement for these subitems were $>90 \%$. For the dynamic reaching subscale, excellent inter-rater reliability coefficients were found for all items. Values for test-retest reliability were moderate to excellent.

The Bland and Altman plots for inter-rater and test-retest agreement are shown in Fig. 1. The mean difference of the total TCMS score between raters was $-0.57(95 \% \mathrm{CI}-5.30$ to 4.16$)$ (Fig. $1 \mathrm{~A})$ and $1.38(95 \% \mathrm{CI}-4.02$ to 6.77$)$ between test and retest (Fig. 1B). Visual inspection revealed no systematic bias.

\subsection{Standard Error of Measurement-Smallest Detectable Difference}

The SEM of the total score was 1.68 (2.9\% of total score) between raters and 1.97 (3.4\%) between test and retest. The SDD was $4.66(8 \%)$ and $5.47(9.4 \%)$ for inter-rater and test-retest results, respectively.

\subsection{Internal consistency}

Cronbach's alpha was 0.94 for total TCMS. For the static sitting balance, selective movement control and dynamic reaching subscales, Cronbach's alpha was $0.82,0.89$ and 0.90 , respectively.

\subsection{Construct validity}

Spearman rank correlation coefficients between TCMS and GMFM are summarized in Table 3. The total score of the GMFM was highly significantly correlated with the total score of the TCMS and with the subtotals of the three subscales, coefficients varying between 0.81 and 0.88 . Correlation analysis with the dimensions of the GMFM revealed no significant correlation with dimension A (lying and rolling). Correlation coefficients with the other dimensions were significant varying between 0.60 and 0.87 . Interestingly, correlation coefficients between the GMFM dimension scores and the total TCMS and its subscales gradually increased from dimension B to E. 
Table 3

Spearman rank correlation coefficients between total Trunk Control Measurement Scale and subscales, and Gross Motor Function Measure total score and dimension scores.

\begin{tabular}{|c|c|c|c|c|c|c|}
\hline \multirow[t]{2}{*}{ TCMS } & \multicolumn{6}{|c|}{ GMFM } \\
\hline & Total & Dimension A & Dimension B & Dimension C & Dimension D & Dimension E \\
\hline Total & $0.88^{\mathrm{a}}$ & 0.25 & $0.67^{\mathrm{b}}$ & $0.77^{\mathrm{a}}$ & $0.85^{\mathrm{a}}$ & $0.89^{\mathrm{a}}$ \\
\hline Static sitting balance & $0.83^{\mathrm{a}}$ & 0.29 & $0.73^{\mathrm{a}}$ & $0.74^{\mathrm{a}}$ & $0.79^{\mathrm{a}}$ & $0.83^{\mathrm{a}}$ \\
\hline Selective movement control & $0.86^{\mathrm{a}}$ & 0.25 & $0.69^{\mathrm{b}}$ & $0.77^{\mathrm{a}}$ & $0.84^{\mathrm{a}}$ & $0.84^{\mathrm{a}}$ \\
\hline Dynamic reaching & $0.81^{\mathrm{a}}$ & 0.17 & $0.60^{c}$ & $0.65^{\mathrm{b}}$ & $0.81^{\mathrm{a}}$ & $0.87^{\mathrm{a}}$ \\
\hline
\end{tabular}

TCMS - Trunk Control Measurement Scale; GMFM - Gross Motor Function Measure; Dimension A - lying and rolling; Dimension B - sitting; Dimension C crawling and kneeling; Dimension D - standing; Dimension E - walking, running and jumping.

a $p$ value $<0001$.

b $p$ value $<0005$.

c $p$ value $<005$.

Table 4

Median and interquartile range of children with CP and TD children for the subscales and total TCMS scores.

\begin{tabular}{|c|c|c|c|c|c|}
\hline & \multicolumn{2}{|c|}{ Children with CP } & \multicolumn{2}{|c|}{ TD children } & \multirow[t]{2}{*}{$p$} \\
\hline & Median & IQR & Median & IQR & \\
\hline Static sitting balance (score $0-20$ ) & 17 & $16-18$ & 20 & $20-20$ & $<0.0001$ \\
\hline Selective movement control (score $0-28$ ) & 13 & $10-16$ & 24 & $22-27$ & $<0.0001$ \\
\hline Dynamic reaching (score $0-10$ ) & 4 & $1-9$ & 10 & $10-10$ & $<0.0001$ \\
\hline Total TCMS (score $0-58$ ) & 33.5 & $25-42$ & 53.5 & $51-57$ & $<0.0001$ \\
\hline
\end{tabular}

TCMS - Trunk Control Measurement Scale; IQR - interquartile range; $p$ - $p$-value.

\subsection{Discriminant ability}

Descriptive statistics for the subscales and total TCMS scores for children with CP and TD children are presented in Table 4. The median total TCMS score for children with CP was 33.5 and 53.5 for the TD children. Statistical analysis revealed a highly significant difference for the total score between both groups $(p<0.0001)$. Also, for the three subscales significantly lower scores were obtained in the children with $\mathrm{CP}(p<0.0001)$. For the TD children, the median score for the subscale static sitting balance was 20 and for the subscale dynamic reaching 10 which corresponds to the maximum scores for these subscales. Also the values of the interquartile range (IQR) equalled the maximum score. For the subscale selective movement control, a median score of 24 out of 28 was found and IQR values were 22-27.

\section{Discussion}

Because of the discrepancy between the clinical relevance of static and dynamic trunk control and the lack of a tool to quantify both aspects, our aim was to develop a standardized scale for trunk control in children with CP and to examine its psychometric properties.

The TCMS total and subscale scores demonstrated excellent inter-rater and test-retest reliability with all ICCs exceeding 0.90. Our results are comparable with values reported for the TIS for people with stroke (Verheyden et al., 2004), as well as with other measures for children with CP, such as the GMFM (Russell, Rosenbaum, Gowland, \& Hardy, 1993), the PDMS-2 (Wang, Liao, \& Hsieh, 2006) and SATCo (Butler, Saavedra, Sofranac, Jarvis, \& Woollacott, 2010). Overall, subscale items showed moderate to excellent inter-rater and test-retest agreement.

Based on our results, item 9 needs specific attention. This item evaluates the performance of lateral shortening and lengthening of the trunk during unilateral lifting of the pelvis. Firstly, due to the problems with selectivity that children with $\mathrm{CP}$ experience, this is a difficult item to perform, but also to evaluate, resulting in a lower test-retest and inter-rater agreement. Furthermore, skewed distributions of scores also partially explain lower kappa values. Nevertheless, the content of this item is clinically relevant for treatment in children with $\mathrm{CP}$ and therefore this item was retained. To improve standardization, a test instruction was added, i.e. the rater should attain additional manual feedback if upward movement of the pelvis is not observed.

For some subitems, kappa values could not be calculated because of skewed distribution of data. Cohen's kappa is not an appropriate statistic if there is a large proportion of agreement and if most of that agreement is limited to only one of the possible rating choices (Haas, 1991). Nevertheless, high percentages of agreement indicate good agreement for these subitems.

In our study, small SEM and SDD for inter-rater and test-retest results were found. These results are confirmed by the results of the Bland and Altman analysis. This supports the use of the TCMS in longitudinal and intervention studies. Cronbach's alpha for the total scale and subscales approached the criterion value of 0.90 and support the underlying construct of our scale.

The GMFM was chosen to determine construct validity of the TCMS. The performance of gross motor activities such as rolling, sitting, walking and jumping, evaluated by the GMFM, all assume appropriate underlying trunk control. For this 
study, we preferred the 88-item GMFM instead of the more recently developed 66-item version (Russell et al., 2000). The shorter version only contains a total score and, as a consequence, information on the different dimensions would not be available. The results of this study showed a highly positive correlation between the total score of the GMFM and the total TCMS score and its three subscales, supporting the construct validity of the TCMS. All dimension scores also correlated significantly with the total TCMS and the subscales, except dimension A (lying and rolling). This is not a surprising result, as items of dimension A evaluate the child's ability to perform functional activities in supine or prone. One could have expected the highest correlation between the TCMS and dimension B of the GMFM, evaluating items in sitting like the TCMS. The different requirements of the sitting position of the GMFM, allowing support from the lower limbs which influences the performance at trunk level, might explain the moderate correlation with the TCMS total score (0.67). Interestingly, we found an increasing correlation between the TCMS and the subsequent dimensions of the GMFM. We hereby assume that these items contain gradually more involvement of the trunk from sitting to walking (Table 3). Furthermore, the highest correlation with dimension B (sitting) was found with the subscale static sitting balance (0.73). Dimension C (crawling and kneeling) and D (standing) correlated the most with the subscale selective movement control ( 0.77 and 0.84 , respectively) and dimension E (walking, running and jumping) showed the highest correlation with subscale dynamic reaching (0.87). These findings suggest that the different subscales of the TCMS contain elements of trunk control that are reflected in different functional activities, measured by the dimensions of the GMFM. Our results therefore support the clinical value of the TCMS as a tool that evaluates several aspects of trunk control.

To examine the discriminant ability, the TCMS was also assessed in TD children. According to Guillemin, Briançon, and Pourel (1992), the discriminant ability of an instrument is defined by the ability to differentiate between persons with a disorder and healthy individuals. Comparison of the TCMS between children with CP and TD children revealed a marked lower performance for the children with $\mathrm{CP}$ for all three subscales and the total score. Thus, these results support the discriminant ability of our scale. Further analysis of the TD children showed a maximal performance for the subscales static sitting balance and dynamic reaching, which was not the case for the subscale selective movement control. Inspection of the data for the latter subscale revealed lower scores for the younger children (8-10 years), while submaximal to maximal scores (27 and 28) were obtained from the age of 11 years onwards. These findings suggest an age related or maturation effect on this subscale and may indicate that selective movements are more difficult to perform. Also, other authors have reported possible changes in postural control fine-tuning strategies until the age of 11 years and even older (de Graaf-Peters et al., 2007; Hadders-Algra \& Brogren, 2008). Future research in larger study groups is needed to further study the possible maturation effects of trunk control.

In this study the TCMS was developed as a new tool to assess trunk control in children with CP. Assessment of the scale revealed good psychometric characteristics. Still, this study warrants some critical reflections. Firstly, the age range of the participants in our study was 8-15 years. Before the age of 8 years, development of postural adjustments during voluntary activity is still in a transitional phase (Forssberg \& Nashner, 1982; Hadders-Algra \& Brogren, 2008). An immature and more variable performance in trunk control was also observed during our pilot study in young TD children. Therefore, considering the development of the TCMS, we first focused on children who, from a developmental perspective, would have reached a more mature stage of postural control. This was confirmed by the results of the TD children on the subscales static sitting balance and dynamic reaching. Still, a next challenging step could be to determine the psychometric properties of the TCMS for a younger age group.

A second limitation concerns the inclusion criterion of the diagnosis of spastic CP, hereby excluding other types such as dyskinetic and ataxic CP. However, the spastic subgroup accounts for almost $80 \%$ of the total population of children with CP (Bax, Tydeman, \& Flodmark, 2006). Dyskinetic CP is characterized by involuntary, stereotyped movements; ataxic CP features a problem with muscle coordination. The clinical characteristics of these patient groups may require specific adaptations of the TCMS.

Finally, the TCMS is suitable for children who can maintain a sitting position, therefore focusing on GMFCS level I to III. Children with lower functional levels (IV and V) might better be evaluated with an evaluation tool that does not require independent sitting, such as the SATCo (Butler, Saavedra, Sofranac, Jarvis, \& Woollacott, 2010).

Despite these limitations, variation in functional abilities was present in our patient group, reflected by the distribution over the first three GMFCS levels and the range of GMFM scores.

\section{Conclusion}

This study reported on the development of a new measurement scale for trunk control in children with CP, the TCMS. The good psychometric properties support the use of the TCMS as an evaluative tool. The use of qualitative items in the TCMS may also facilitate clinical implementation of this measurement scale because it provides an overview of the strengths and weaknesses of the child's trunk performance. Future studies should address responsiveness of the scale to interventions, as well as application to a younger age group and to other populations of CP.

\section{Conflict of interest statement}

The authors declare that the research is conducted in the absence of any commercial or financial relationships that could be construed as a potential conflict of interest. 


\section{Acknowledgements}

Lieve Heyrman received a PhD fellowship of the Research Foundation Flanders (FWO). The authors would like to thank the children and their parents for their cooperation, and the staff of the participating centres (Windekind, Leuven - St. Jozef Institute, Antwerp) and private practices (R. Cuppers - N. Van Aerschot - J. Weyne) for their collaboration.

\section{Appendix A. Trunk Control Measurement Scale (TCMS)}

\section{Test instructions}

Orthoses, shoes and/or a trunk brace should be taken off.

The starting position is the same for each item. The patient is sitting on the edge of a treatment table without back, arm or feet support. The thighs make full contact with the table.

The hands rest on the legs, close to the body. The patient is asked to sit upright at the start of each item and needs to be encouraged to maintain the upright position during the performance of the task. The term 'upright' refers to the most upright sitting position that the child can assume. This position can differ from child to child. This position is the reference position for identification of aberrations in performance and/or compensations.

Each item is performed three times. The best performance is taken into account for scoring.

If the child performs the tasks of subscale 'static sitting balance' with single arm support, only support with the hand flat on the table without grasping is allowed.

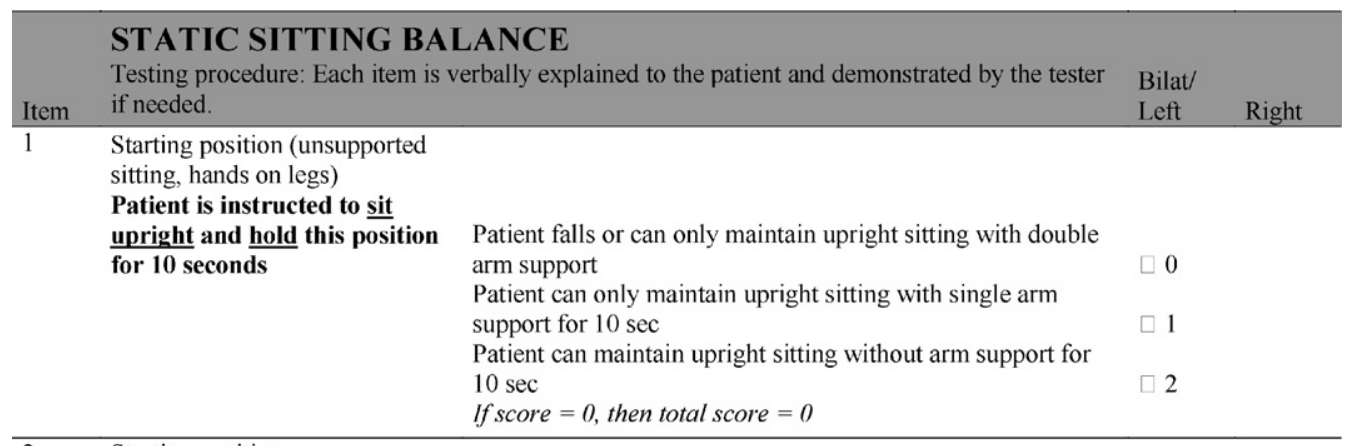

\begin{tabular}{|c|c|c|c|c|}
\hline 2 & $\begin{array}{l}\text { Starting position } \\
\text { Patient lifts both arms at eye } \\
\text { height in one second and } \\
\text { returns to starting position }\end{array}$ & $\begin{array}{l}\text { Patient falls or can not lift arms } \\
\text { Patient can lift arms without falling but with compensations. } \\
\text { Possible compensations are: } \\
\text { (1) backward lean, (2) increase of trunk flexion, (3) lateral } \\
\text { flexion, (4) other } \\
\text { Patient lifts arms without compensations }\end{array}$ & $\square 0$ & \\
\hline \multirow[t]{4}{*}{3} & & & & \\
\hline & $\begin{array}{l}\text { Therapist crosses one leg over } \\
\text { the other leg }\end{array}$ & $\begin{array}{l}\text { Patient falls, can not cross legs or can only maintain sitting } \\
\text { with double arm support }\end{array}$ & $\square 0$ & $\square 0$ \\
\hline & & Patient can maintain sitting with single arm support for $10 \mathrm{sec}$ & $\sqcup 1$ & $\sqcup 1$ \\
\hline & & Patient can maintain sitting without arm support for $10 \mathrm{sec}$ & $\sqcup 2$ & $\sqcup 2$ \\
\hline \multirow[t]{3}{*}{4} & $\begin{array}{l}\text { Starting position } \\
\text { Patient crosses one leg over } \\
\text { the other leg (assistance with } \\
\text { one hand is allowed) } \\
\text { 'minimal' = small trunk movements } \\
\text { without signs of imbalance of trunk } \\
\text { during movement of leg } \\
\text { "clear' = clear signs of imbalance } \\
\text { i.e. lateral flexion or flexion of trunk }\end{array}$ & $\begin{array}{l}\text { Patient falls, can not cross legs or can only cross legs with } \\
\text { double arm support }\end{array}$ & $\square 0$ & $\square 0$ \\
\hline & & $\begin{array}{l}\text { Patient can only cross legs with single arm support } \\
\text { Patient crosses legs without arm support but with clear trunk } \\
\text { displacement }\end{array}$ & $\square 1$ & $\square 1$ \\
\hline & & Patient crosses legs with minimal trunk displacement & $\square 3$ & $\square 3$ \\
\hline
\end{tabular}




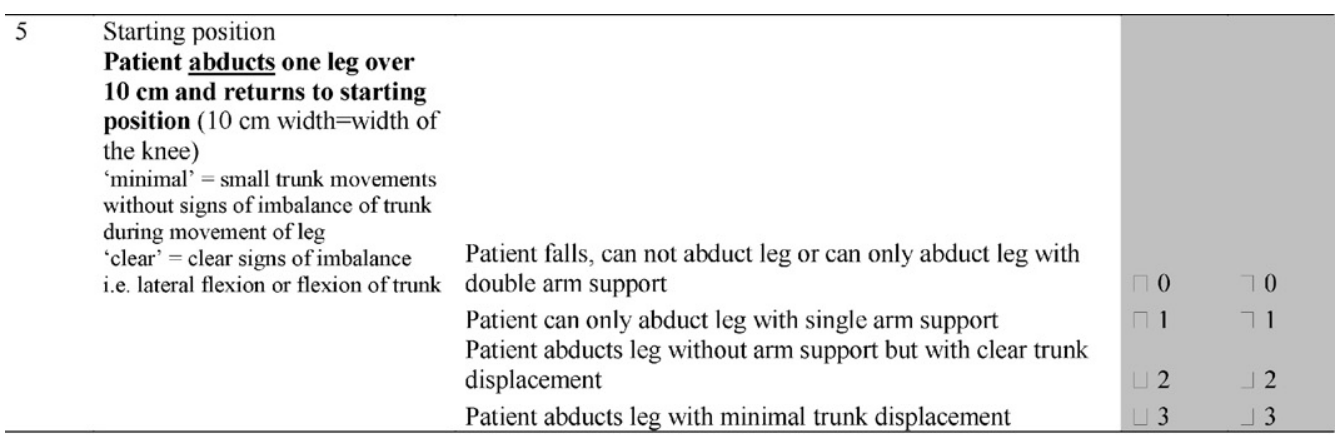

Total static sitting balance

\section{DYNAMIC SITTING BALANCE}

\section{Selective movement control}

Testing procedure: First, each item is verbally explained and demonstrated by the tester

Secondly, the item is demonstrated on the patient with manual guidance. Thirdly, the patient is asked to perform the expected movement under manual guidance of the tester. Then, the patient performs the item on its own in three attempts.

Starting position - arms crossed

6a $\quad \begin{aligned} & \text { Starting p } \\ & \text { over chest }\end{aligned}$

Patient is instructed to lean

forward with a fixed trunk for approximately $45^{\circ}$ and return to starting position

normal righting reaction of the head

i.e. limited head extension is not

scored as a compensation

Patient falls or can not reach target position $\quad \square 0$

Patient can lean forward

If score $=0$, then item $6 b=0$

\begin{tabular}{|c|c|c|c|c|}
\hline \multirow[t]{2}{*}{$6 b$} & & $\begin{array}{l}\text { Patient compensates (1) increased head extension, } \\
\text { (2) increased trunk flexion, (3) increased lumbar lordosis, } \\
\text { (4) increased knee flexion, (5) other }\end{array}$ & \multicolumn{2}{|l|}{$\square 0$} \\
\hline & & Patient leans forward without compensations & $\square 1$ & \\
\hline $7 \mathrm{a}$ & $\begin{array}{l}\text { Starting position - arms crossed } \\
\text { over chest } \\
\text { Patient is instructed to lean } \\
\text { backward with a fixed trunk } \\
\text { for approximately } \mathbf{4 5}^{\circ} \text { and } \\
\text { return to starting position } \\
\text { normal righting reaction of the head } \\
\text { i.e. limited head flexion is not } \\
\text { scored as a compensation }\end{array}$ & $\begin{array}{l}\text { Patient falls or can not reach target position } \\
\text { Patient can lean backward } \\
\text { If score }=0 \text {, then item } 7 b=0\end{array}$ & $\begin{array}{r}\square 0 \\
\square 1\end{array}$ & \\
\hline $7 b$ & & $\begin{array}{l}\text { Patient compensates (1) increased head flexion, (2) increased } \\
\text { trunk flexion, (3) increased knee extension, (4) other }\end{array}$ & $\square 0$ & \\
\hline & & Patient leans backward without compensations & $\square 1$ & \\
\hline $8 \mathrm{a}$ & $\begin{array}{l}\text { Starting position } \\
\text { Patient is instructed to touch } \\
\text { the table with the elbow at } \\
\text { level of the femoral head (by } \\
\text { shortening the ipsilateral side } \\
\text { and lengthening the } \\
\text { contralateral side) and return } \\
\text { to starting position }\end{array}$ & $\begin{array}{l}\text { Patient falls or does not touch the table with the elbow } \\
\text { Patient can touch the table with the elbow } \\
\text { If score }=0 \text {, then item } 8 b \text { and } 8 c=0\end{array}$ & $\begin{array}{r}\square 0 \\
\square 1\end{array}$ & $\begin{array}{r}\square 0 \\
\square 1\end{array}$ \\
\hline
\end{tabular}




\begin{tabular}{|c|c|c|c|c|}
\hline \multirow[t]{2}{*}{$8 \mathrm{~b}$} & & $\begin{array}{l}\text { Patient demonstrates (1) no shortening/lengthening or } \\
\text { (2) opposite shortening/lengthening }\end{array}$ & $\square 0$ & $\square 0$ \\
\hline & & $\begin{array}{l}\text { Patient demonstrates expected shortening/lengthening } \\
\text { If score }=0, \text { then item } 8 c=0\end{array}$ & $\sqcup 1$ & $\sqcup 1$ \\
\hline \multirow[t]{2}{*}{$8 \mathrm{c}$} & & $\begin{array}{l}\text { Patient compensates: (1) increased trunk flexion, (2) forward } \\
\text { or backward lean, (3) pelvic lift, (4) other }\end{array}$ & $\square 0$ & $\square 0$ \\
\hline & & Patient touches the table without compensations & $\square 1$ & $\square 1$ \\
\hline \multirow[t]{2}{*}{$9 \mathrm{c}$} & & $\begin{array}{l}\text { Patient compensates: (1) contralateral head flexion, } \\
\text { (2) marked lateral trunk displacement, (3) other }\end{array}$ & $\square 0$ & $\square 0$ \\
\hline & & Patient lifts the pelvis without compensations & $\square 1$ & $\square 1$ \\
\hline $10 \mathrm{a}$ & $\begin{array}{l}\text { Starting position - arms crossed } \\
\text { over chest } \\
\text { Patient is instructed to rotate } \\
\text { the upper trunk three times } \\
\text { with head fixated in starting } \\
\text { position. The movement is } \\
\text { initiated from the shoulder } \\
\text { girdle. }\end{array}$ & $\begin{array}{l}\text { Patient ( } 1 \text { ) falls, (2) can not rotate the upper trunk i.e. patient } \\
\text { can not perform the rotation movement, even not with the } \\
\text { entire trunk, or ( } 3 \text { ) demonstrates no selective rotation of the } \\
\text { upper trunk (en bloc) } \\
\text { Patient demonstrates partial selective rotation of the upper } \\
\text { trunk (partial = asymmetrical, small ROM, more shoulders than } \\
\text { trunk) } \\
\text { Patient demonstrates expected selective rotation of the upper } \\
\text { trunk } \\
\text { If score }=0 \text {, then item } 10 \mathrm{~b}=0\end{array}$ & $\begin{array}{l}\square 1 \\
\square 2\end{array}$ & \\
\hline $10 \mathrm{~b}$ & & $\begin{array}{l}\text { Patient rotates the upper trunk with head rotation } \\
\text { Patient rotates the upper trunk without head rotation }\end{array}$ & $\begin{array}{l}\sqcup 0 \\
\square 1 \\
\end{array}$ & \\
\hline $11 \mathrm{a}$ & $\begin{array}{l}\text { Starting position - arms crossed } \\
\text { over chest } \\
\text { Patient is instructed to rotate } \\
\text { the lower trunk three times } \\
\text { with head fixated in starting } \\
\text { position. The movement is } \\
\text { initiated from the pelvic girdle. }\end{array}$ & $\begin{array}{l}\text { Patient ( } 1 \text { ) falls, (2) can not rotate the lower trunk i.e. patient } \\
\text { can not perform the rotation movement, even not with the } \\
\text { entire trunk, or ( } 3 \text { ) demonstrates no selective rotation of the } \\
\text { lower trunk (en bloc) } \\
\text { Patient demonstrates partial selective rotation of the lower } \\
\text { trunk (partial = asymmetrical, small ROM, additional movement of } \\
\text { upper trunk) } \\
\text { Patient demonstrates expected selective rotation of the lower } \\
\text { trunk } \\
\text { If score }=0 \text {, then item } 11 \mathrm{~b}=0\end{array}$ & $\square 2$ & \\
\hline $11 \mathrm{~b}$ & & $\begin{array}{l}\text { Patient compensates with pelvic tilt } \\
\text { Patient rotates the lower trunk without compensations }\end{array}$ & $\begin{array}{l}\square 0 \\
\square 1\end{array}$ & \\
\hline
\end{tabular}


Patient falls or can not shuffle the pelvis in forward and

backward direction i.e. no displacement of the body in either

direction

Patient can partially shuffle the pelvis (partial = with mainly lateral flexion and little rotation; small ROM; takes a lot of effort) Patient can shuffle the pelvis by use of both lateral flexion and rotation in one direction and partially in the other direction

Patient can shuffle the pelvis by use of both lateral flexion and rotation in both directions

If score $=0$, then item $12 b=0$

\begin{tabular}{lll}
\hline $12 \mathrm{~b}$ & Patient compensates with excessive trunk displacement & $\square 0$ \\
& Patient shuffles pelvis without compensations & $\Pi 1$ \\
\hline
\end{tabular}

\begin{tabular}{|c|c|c|c|c|}
\hline & $\begin{array}{l}\text { Dynamic reaching (equi } \\
\text { Testing procedure: Each item is ve } \\
\text { by the patient. }\end{array}$ & $\begin{array}{l}\text { librium reactions) } \\
\text { erbally explained by the tester and then performed three times }\end{array}$ & $\begin{array}{l}\text { Bilat/ } \\
\text { Left }\end{array}$ & Right \\
\hline 13 & $\begin{array}{l}\text { Starting position - arms straight } \\
\text { forward } \\
\text { Patient is instructed to reach } \\
\text { forward with both arms } \\
\text { straight to target at eye level } \\
\text { positioned at a distance, } \\
\text { corresponding with the } \\
\text { forearm length and return to } \\
\text { starting position }\end{array}$ & $\begin{array}{l}\text { Patient falls or can not reach target } \\
\text { Patient reaches target, but has difficulties in performance. } \\
\text { Difficulties are: (1) takes a lot of effort i.e. slow and with } \\
\text { difficulty or (2) uses some support of hand when approaching } \\
\text { the starting position } \\
\text { Patient reaches target and returns to starting position without } \\
\text { difficulties }\end{array}$ & $\begin{array}{l}\cup 1 \\
\square 2\end{array}$ & \\
\hline 14 & $\begin{array}{l}\text { Starting position - one arm } \\
\text { straight sideward and other hand } \\
\text { on leg } \\
\text { Patient is instructed to reach } \\
\text { sideward with one arm } \\
\text { straight to target at eye level } \\
\text { positioned at a distance, } \\
\text { corresponding with the } \\
\text { forearm length and return to } \\
\text { starting position }\end{array}$ & $\begin{array}{l}\text { Patient falls or can not reach target } \\
\text { Patient reaches target, but has difficulties in performance. } \\
\text { Difficulties are: (1) takes a lot of effort i.e. slow and with } \\
\text { difficulty or (2) uses some support of hand when approaching } \\
\text { the starting position } \\
\text { Patient reaches target and returns to starting position without } \\
\text { difficulties }\end{array}$ & $\begin{array}{l}\square 1 \\
\square 2\end{array}$ & $\begin{array}{l}\beth 1 \\
\square 2\end{array}$ \\
\hline 15 & $\begin{array}{l}\text { Starting position - one arm } \\
\text { straight sideward and other hand } \\
\text { on leg } \\
\text { Patient is instructed to reach } \\
\text { across the midline with one } \\
\text { arm (reach to the opposite } \\
\text { side) and return to starting } \\
\text { position. The target is } \\
\text { positioned at eye level at a } \\
\text { distance corresponding with half } \\
\text { the forearm length of the } \\
\text { reaching arm. }\end{array}$ & $\begin{array}{l}\text { Patient falls or can not reach target } \\
\text { Patient reaches target, but has difficulty in performance. } \\
\text { Difficulties are: (1) takes a lot of effort i.e. slow and with } \\
\text { difficulty or (2) uses some support of hand when approaching } \\
\text { the starting position } \\
\text { Patient reaches target and returns to starting position without } \\
\text { difficulties }\end{array}$ & $\begin{array}{l}\square 1 \\
\square 2\end{array}$ & $\begin{array}{l}\square 1 \\
\square 2\end{array}$ \\
\hline
\end{tabular}

Total dynamic reaching

\section{References}

Bartlett, D., \& Birmingham, T. (2003). Validity and reliability of a pediatric reach test. Pediatric Physical Therapy, 15, 84-92.

Bartlett, D., \& Purdie, B. (2005). Testing of the spinal alignment and range of motion measure: A discriminative measure of posture and flexibility for children with cerebral palsy. Developmental Medicine and Child Neurology, 47, 739-743. 
Bax, M., Tydeman, C., \& Flodmark, O. (2006). Clinical and MRI correlates of cerebral palsy: The European Cerebral Palsy Study. The Journal of the Medical Association, 296, 1602-1608.

Bland, J. M., \& Altman, D. G. (1986). Statistical methods for assessing agreement between two methods of clinical measurement. The Lancet, 1, 307-310.

Butler, P. B., Saavedra, S., Sofranac, M., Jarvis, S. E., \& Woollacott, M. H. (2010). Refinement, reliability, and validity of the segmental assessment of trunk control. Pediatric Physical Therapy, 22, 246-257.

Carr, J. H., \& Sheperd, R. B. (1998). Neurological rehabilitation: Optimizing motor performance (2nd ed.). Oxford: Butterworth-Heinemann.

Damiano, D. L., Alter, K. E., \& Chambers, H. (2009). New clinical and research trends in lower extremity management for ambulatory children with cerebral palsy. Physical Medicine and Rehabilitation Clinics of North America, 20, 469-491.

de Graaf-Peters, V. B., Blauw-Hospers, C. H., Dirks, T., Bakker, H., Bos, A. B., \& Hadders-Algra, M. (2007). Development of postural control in typically developing children and children with cerebral palsy: Possibilities for intervention? Neuroscience and Biobehavioral Reviews, 31, 1120-1191.

Fife, S. E., Roxborough, L. A., Armstrong, R. W., Harris, S. R., Gregson, J. L., \& Field, D. (1991). Development of a clinical measure of postural control for assessment of adaptive seating in children with neuromotor disabilities. Physical Therapy, 71, 981-993.

Forssberg, H., \& Nashner, L. M. (1982). Ontogenetic development of postural control in man: Adaptation to altered support and visual conditions during stance. The Journal of Neuroscience, 2, 545-552.

Franjoine, M. R., Gunther, J. S., \& Taylor, M. J. (2003). Pediatric balance scale: A modified version of the berg balance scale for the school-age child with mild to moderate motor impairment. Pediatric Physical Therapy, 15, 114-128.

Guillemin, F., Briançon, S., \& Pourel, J. (1992). Validity and discriminant ability of the HAQ Functional Index in early rheumatoid arthritis. Disability and Rehabilitation, 14, 71-77.

Haas, M. (1991). Statistical methodology for reliability studies. Journal of Manipulative and Physiological Therapeutics, 14, 119-132.

Hadders-Algra, M., \& Brogren, E. (2008). Postural control: A key issue in developmental disorders (1st ed.). London: MacKeith Press.

Hinkle, D. E., Wiersma, W., \& Jurs, S. G. (1998). Applied statistics for behavioral sciences (2nd ed.). Boston: Houghton Mifflin.

Klingels, K., De Cock, P., Molenaers, G., Desloovere, K., Huenaerts, C., Jaspers, E., et al. (2010). Upper limb motor and sensory impairments in children with hemiplegic cerebral palsy. Can they be measured reliably? Disability and Rehabilitation, 32, 409-416.

Landis, J. R., \& Koch, G. G. (1977). The measurement of observer agreement for categorical data. Biometrics, 33, 159-174.

Palisano, R., Rosenbaum, P., Walter, S., Russell, D., Wood, E., \& Galuppi, B. (1997). Development and reliability of a system to classify gross motor function in children with cerebral palsy. Developmental Medicine and Child Neurology, 39, 214-223.

Portney, L. G., \& Watkins, M. P. (2009). Foundations of clinical research: Application to practice (3rd ed.). New Jersey: Pearson Prentice Hall.

Prosser, L. A., Lee, S. C., VanSant, A. F., Barbe, M. F., \& Lauer, R. T. (2010). Trunk and hip muscle activation patterns are different during walking in young children with and without cerebral palsy. Physical Therapy, 90, 986-997.

Russell, D. J., Avery, L. M., Rosenbaum, P. L., Raina, P. S., Walter, S. D., \& Palisano, R. J. (2000). Improved scaling of the gross motor function measure for children with cerebral palsy: Evidence of reliability and validity. Physical Therapy, 80, 873-885.

Russell, D. J., Rosenbaum, P., Gowland, C., \& Hardy, S. (1993). Manual for the gross motor function measure. Hamilton: McMaster University.

Sæther, R., \& Jørgensen, L. (2011). Intra- and inter-observer reliability of the Trunk Impairment Scale for children with cerebral palsy. Research in Developmental Disabilities, 32, 727-739.

Stamer, M. (2000). Posture and movement of the child with cerebral palsy (1st ed.). United States of America: Therapy Skill Builders.

van der Heide, J. C., Fock, J. M., Otten, B., Stremmelaar, E., \& Hadders-Algra, M. (2005). Kinematic characteristics of postural control during reaching in preterm children with cerebral palsy. Pediatric Research, 58, 586-593.

Verheyden, G., Nieuwboer, A., Mertin, J., Preger, R., Kiekens, C., \& De Weerdt, W. (2004). The Trunk Impairment Scale: A new tool to measure motor impairment of the trunk after stroke. Clinical Rehabilitation, 18, 326-334.

Verheyden, G., Nieuwboer, A., Van de Winckel, A., \& De Weerdt, W. (2007). Clinical tools to measure trunk performance after stroke: A systematic review of the literature. Clinical Rehabilitation, 21, 387-394.

Wang, H. H., Liao, H. F., \& Hsieh, C. L. (2006). Reliability, sensitivity to change, and responsiveness of the peabody developmental motor scales-second edition for children with cerebral palsy. Physical Therapy, 86, 1351-1359. 